\title{
O CADASTRO AMBIENTAL RURAL (CAR)E SEUS DESAFIOS PARA A EFETIVA PROTEÇÃO DO MEIO AMBIENTE
}

\author{
THE RURAL ENVIRONMENTAL REGISTRY (CAR) AND ITS CHALLENGES FOR \\ EFFECTIVE PROTECTION OF THE ENVIRONMENT
}

\section{EL CATASTRO AMBIENTAL RURAL (CAR) Y SUS DESAFÍOS PARA LA EFECTIVA PROTECCIÓN DEL MEDIO AMBIENTE}

\section{Délton Winter de Carvalho'}

\section{Kelly de Souza Barbosa²}

Licença CC BY:

Artigo distribuído sob os termos Creative Commons, permite uso e distribuição irrestrita em qualquer meio desde que o autor credite a fonte original.

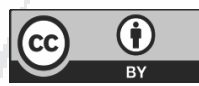

\begin{abstract}
Resumo:Tencionando otimizar e utilizar novas tecnologias para a desafiante catalogação de imóveis rurais no Brasil, o Código Florestal normatizou o Cadastro Ambiental Rural e o Sistema de Cadastro Ambiental Rural. E após cerca de seis anos da promulgação da lei, qual a viabilidade deste cadastramento como instrumento de políticas públicas para proteção ambiental? Utilizando a pesquisa bibliográfica e documental e os métodos descritivo-dedutivo, analisaram-se este cadastro e o que poderia prejudicar sua plena efetivação, dado que há a tendência de prorrogações pelo governo do prazo final para o cadastramento, dificultando a sua integralidade e a colaboração para a proteção ambiental.
\end{abstract}

Palavras-chave: Cadastro Ambiental Rural; Sistema de Cadastro Ambiental Rural; desafios; prorrogações; proteção ambiental.

Graduado pela Universidade do Vale do Rio dos Sinos (1999). Mestre (2001) e Doutor (2006) em Direito pela Universidade do Vale do Rio dos Sinos. Pós-Doutor em Direito Ambiental e Direito dos Desastres pela University of California, Berkeley, CA, USA (2013), sob a orientação de Daniel A. Farber. Atualmente é Professor Adjunto I no Programa de Pós-Graduação em Direito (PPGD) da Universidade do Vale do Rio dos Sinos. Membro da Associação Brasileira dos Professores de Direito Ambiental (APRODAB) e do Instituto o Direito por um Planeta Verde. Membro do Conselho Editorial da Revista Brasileira de Direito Ambiental e da Revista Direito Ambiental e Sociedade. Líder do Grupo de Pesquisa Direito, Risco e Ecocomplexidade. Advogado. E-mail: delton@deltoncarvalho.com.br

2 Doutoranda em Direito pela Universidade do Vale do Rio dos Sinos (UNISINOS), com bolsa CAPES/PROEX, na modalidade taxa. Mestra em Direitos Coletivos e Cidadania pela Universidade de Ribeirão Preto (UNAERP), com bolsa CAPES/PROSUP, na modalidade mensalidade (2018). Especialista em Direito Processual Civil e Processo Cautelar pela Universidade Cândido Mendes (UCAM) - Instituto Prominas (2017). Bacharela em Direito pela Universidade do Estado de Minas Gerais (UEMG), Unidade Passos (2015). Membro do Grupo de Pesquisa Direito, Risco e Ecocomplexidade. Advogada. E-mail: kelly_sbarbosa@ hotmail.com 
Abstract: With the aim of optimizing and using new technologies for the challenging cataloging of rural properties in Brazil, the Forest Code has regulated the Rural Environmental Registry and Rural Environmental Registration System. Around six years since the enactment of the law, what is the feasibility of this registration as an instrument of public policies for environmental protection? Using bibliographical and documental research and descriptive-deductive methods, this registry was analyzed, seeking to identify aspects that could be hindering its full effectiveness. It is noted that tendency of the government to extend the deadline for registration makes it difficult to integrate the system for collaboration in environmental protection.

Keywords: Rural Environmental Registry; Rural Environmental Registration System; challenges; extensions; environmental Protection.

Resumen: Con la intención de optimizar y utilizar las nuevas tecnologías para la desafiante catalogación de inmuebles rurales en Brasil, el Código Forestal estandarizó el Catastro Ambiental Rural y el Sistema de Catastro Ambiental Rural. Y después de seis años de la promulgación de la ley, ¿cuál es la viabilidad de este registro en el catastro como instrumento de políticas públicas para protección ambiental? Utilizando la investigación bibliográfica y documental y los métodos descriptivo deductivo, se analizó este catastro y lo que podría perjudicar su plena efectuación, dado que la tendencia de prorrogaciones por el gobierno del plazo final para el registro, dificultando su integridad y la colaboración para la protección ambiental.

Palabras-clave: Catastro Ambiental Rural; Sistema de Catastro Ambiental Rural; desafíos; prorrogaciones; protección ambiental.

\section{INTRODUÇÃO}

Haja vista as tentativas infrutíferas ou de pouca repercussão da catalogação dos imóveis rurais e das áreas ambientais tuteladas desde 1964 (ano da promulgação do Estatuto da Terra), o Código Florestal (Lei n 12.651, de 25 de maio de 2012) cria o Cadastro Ambiental Rural (CAR) e seu respectivo Sistema de Cadastro Ambiental Rural (SICAR), no âmbito do Sistema Nacional de Informações sobre o Meio Ambiente (SINIMA).

Tais instrumentos, regulamentados pelo Decreto $n^{\circ} 7.830 / 2012$, visam otimizar e compartilhar virtualmente as informações sobre os imóveis rurais nacionais. Dessa forma, a regularização ambiental das propriedades rurais se tornaria factível e escorreita, assim como o monitoramento das áreas ambientais.

Logo, indaga-se: Após aproximadamente 6 (seis) anos da promulgação do Código Florestal, qual a viabilidade do Cadastro Ambiental Rural (CAR) como instrumento de políticas públicas para proteção ambiental? 
Utilizando a pesquisa bibliográfica e documental associando-as com os métodos descritivo e dedutivo, tem-se como objetivo a análise do códex florestal acerca do Cadastro Ambiental Rural (CAR) dos dados estatísticos sobre o cadastramento e dos motivos estatais que poderiam estar prejudicando sua plena efetivação.

No primeiro capítulo foi contextualizado o histórico de catalogação dos imóveis rurais no Brasil. No segundo capítulo, abordou-se a atual normatização do Cadastro Ambiental Rural (CAR) e seu respectivo sistema, o SICAR, no Código Florestal de 2012, sendo dedicados dois subcapítulos, um para o procedimento de inscrição no CAR/SICAR e o outro sobre os possíveis entraves para a sua total implantação.

De fato, a ferramenta possui índices satisfatórios de implantação e a plataforma digital do CAR/SICAR condiz com a realidade brasileira e com as novas tecnologias, tornando mais transparente, célere, econômico e acessível o processo de cadastramento dos imóveis rurais e de localização das áreas ambientais juridicamente tuteladas.

Todavia, as medidas procrastinatórias realizadas pelo próprio Estado, aqui se enfatiza a demora na regulamentação do sistema, as expedições de Medidas Provisórias convertidas em Lei para prorrogar o prazo de inscrição no CAR/SICAR e os Projetos de Lei em trâmite para postergar ainda mais este termo final de regularização das propriedades rurais, dificultaram e continuam dificultando a integralidade do cadastramento e, por conseguinte, a efetiva proteção ambiental.

\section{CATALOGAÇÃO DOS IMÓVEIS RURAIS BRASILEIROS}

As dificuldades de catalogação dos imóveis rurais brasileiros remontam ao sistema de capitanias hereditárias portuguesas e à ausência de uma regulamentação escorreita das propriedades rurais até 1964, ano da promulgação do Estatuto da Terra (Lei $n^{\circ}$ 4.504).

O Estatuto da Terra foi a legislação responsável por criar o Cadastro de Imóveis Rurais do Brasil (artigo 43 e seguintes), primeiramente organizado pelo 


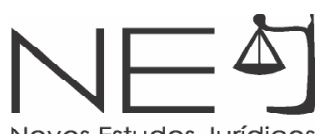

Instituto Brasileiro de Reforma Agrária (IBRA), substituído em 1970 pelo Instituto Nacional de Colonização e Reforma Agrária (INCRA) ${ }^{3}$, que consistia no registro obrigatório de informações do proprietário e dados cartográficos dos imóveis rurais, assim como da exploração e do uso da terra.

Em 1972 foi instituído pela Lei no 5.868 o Sistema Nacional de Cadastro Rural, que apenas englobou o Cadastro de Imóveis Rurais. O imóvel cadastrado neste sistema, ainda vigente, recebe um número de identificação na Certidão de Cadastro de Imóvel Rural (CCIR).

Houve outras tentativas de cadastramento dos imóveis rurais em nível federal e estadual. Todavia, dada a ausência de integração das informações cadastrais - principalmente com os registros públicos ${ }^{4}$-, restou frustrada a real identificação dos imóveis e, consequentemente, as intervenções do Poder Público para a averiguação dos princípios constitucionais, seja da função social da propriedade, seja da proteção ao meio ambiente. Nesse sentido, urge transcrever as ponderações de LASKOS, CAZELLA e REBOLLAR:

Tanto o INCRA quanto os cartórios de registros de imóveis não dispõem de uma base de dados oficiais para confrontar as informações declaradas pelos proprietários de imóveis rurais. Sem essa base, não é possível verificar se as informações declaradas são verdadeiras. No caso do INCRA, somente os imóveis acima de quatro módulos fiscais são fiscalizados. A escolha dos imóveis a serem fiscalizados ocorre de forma aleatória, sendo eleitos por área de atuação. Além disso, a lei não obriga os proprietários de imóveis com menos de quatro módulos fiscais a atualizarem as formas de uso. Assim, os dados cadastrais de todas as propriedades e posses médias e pequenas não são confiáveis e não podem ser utilizados para a gestão socioambiental ou para a elaboração de políticas públicas, nem para monitoramento da aplicação da legislação ambiental. ${ }^{5}$

A Lei n 10.267/2001 estabelece o georreferenciamento dos imóveis rurais,

3 O INCRA resulta da fusão dos seguintes órgãos: IBRA (Instituto Brasileiro de Reforma Agrária), INDA (Instituto Nacional de Colonização e Reforma Agrária) e GEDA (Grupo Executivo de Reforma Agrária). A autarquia foi extinta em 1987 e reincorporada à Administração Pública pós-constituição de 1988.

4 A Lei n 6.015/1973 dispõe sobre os registros públicos e institui o Cartório de Registro de Imóveis.

5 LASKOS, André Arruda; CAZELLA, Ademir Antônio; REBOLLAR, Paola Beatriz May. O Sistema Nacional de Cadastro Rural: história, limitações atuais e perspectivas para a conservação ambiental e segurança fundiária. Desenvolvimento e Meio Ambiente, Curitiba, v. 36, p.189-199, 30 abr. 2016. Disponível em: <http://revistas.ufpr.br/made/article/view/39124>. Acesso em: $01^{\circ}$ jul. 2018. p. 195. 
por isso ela "representa um marco na direção de uma efetiva integração entre cadastro e registro de imóveis porque define a obrigatoriedade do registro de uma planta topográfica e do memorial descritivo do imóvel antes da realização de qualquer mudança de titularidade."6

Atento a essa evolução da catalogação dos imóveis rurais e considerando que um dos objetivos da Política Nacional do Meio Ambiente (PNMA) é "à difusão de tecnologias de manejo do meio ambiente, à divulgação de dados e informações ambientais e à formação de uma consciência pública sobre a necessidade de preservação da qualidade ambiental e do equilíbrio ecológico" (artigo $4^{\circ}$, inciso $\mathrm{V}$, da Lei $n^{\circ}$ 6.938/81), foi criado um importante instrumento de sistematização das informações ambientais chamado de SINIMA. O Sistema Nacional de Informações sobre o Meio Ambiente (SINIMA) ${ }^{7}$ está disposto no artigo 90, inciso VII, da Lei n 6.938/81, regulamentado pelo Decreto n 99.274/1990, alterado pelo Decreto n 3.942/2001, e é o responsável pela gestão das informações ambientais no âmbito do Sistema Nacional do Meio Ambiente (SISNAMA) ${ }^{8}$.

Neste mesmo intuito de organização das informações ambientais das áreas de florestas e vegetação naturais e das áreas rurais consolidadas, a Lei $n^{\circ} 12.651 / 2012$, notadamente conhecida como o Novo Código Florestal ${ }^{9}$ ou simplesmente Código Florestal, inova ao normatizar o Cadastro Ambiental Rural (CAR) aliado ao Sistema de Cadastro Ambiental Rural (SICAR).

Esse instrumento de política ambiental surge "como uma possibilidade

6 LASKOS, André Arruda; CAZELLA, Ademir Antônio; REBOLLAR, Paola Beatriz May. O Sistema Nacional de Cadastro Rural: história, limitações atuais e perspectivas para a conservação ambiental e segurança fundiária. Desenvolvimento e Meio Ambiente, Curitiba, v. 36, p.189-199, 30 abr. 2016. Disponível em: <http://revistas.ufpr.br/made/article/view/39124>. Acesso em: $01^{\circ}$ jul. 2018. p. 194.

7 A Secretária Executiva do Ministério do Meio Ambiente é o órgão responsável pela implementação do Sistema Nacional de Informações sobre o Meio Ambiente (SINIMA), que ainda está "em processo de conceituação e planejamento dos primeiros módulos-pilotos". Ele "pode ser definido como um sistema de informação que irá integrar, por meio de padrões abertos de comunicação de dados (protocolos), um conjunto significativo de informações sobre o Meio Ambiente que atualmente se encontram disponibilizadas de forma isolada nos diferentes órgãos do MMA, vinculadas e integrantes do SISNAMA. Com isso, a sociedade em geral terá acesso a um conjunto de informações sobre o Meio Ambiente produzidas de forma descentralizada mas apresentadas de forma integrada." MMA - Ministério do Meio Ambiente. SINIMA: Sistema Nacional de Informações sobre o meio ambiente. Brasília, 2001. Disponível em: <http://www.mma.gov.br/port/se/sinima/capa/corpo .html>. Acesso em: 03 ago. 2018.

8 O Sistema Nacional do Meio Ambiente (SISNAMA), criado pela Lei 6.938/1981 e regulamentado pelo Decreto $\mathrm{n}^{\circ} 99.274 / 1990$ possui a seguinte estrutura: (a) Órgão Superior: O Conselho de Governo; (b) Órgão Consultivo e Deliberativo: O Conselho Nacional do Meio Ambiente (CONAMA); (c) Órgão Central: O Ministério do Meio Ambiente (MMA); (d) Órgão Executor: O Instituto Brasileiro do Meio Ambiente e dos Recursos Naturais Renováveis (IBAMA); (e) Órgãos Seccionais: os órgãos ou entidades estaduais responsáveis pela execução de programas, projetos e pelo controle e fiscalização de atividades capazes de provocar a degradação ambiental; (f) Órgãos Locais: os órgãos ou entidades municipais, responsáveis pelo controle e fiscalização dessas atividades, nas suas respectivas jurisdições. MMA - Ministério do Meio Ambiente. CONAMA: SISNAMA - Sistema Nacional do Meio Ambiente. Brasília, [2018?]. Disponível em: <http://www.mma.gov.br/port/conama//estr1.cfm>. Acesso em: 03 ago. 2018.

9 A denominação exsurge para diferenciar do revogado Código Florestal, Lei n 4.771/1965. 
de fomento para a formação de corredores ecológicos e para a conservação dos demais recursos naturais, o que contribui para a melhoria da qualidade ambiental"10 e, acrescenta-se, controle pelo Poder Público da efetiva preservação da natureza verde brasileira e regularização dos imóveis rurais.

Em síntese, a regularização ambiental é o conjunto de medidas a serem adotadas pelo proprietário de imóvel rural consolidado ${ }^{11}$ ou não, que esteja em desacordo com a legislação ambiental e, por conseguinte, com a diretriz constitucional (artigo 50, inciso XXIII) da função ambiental da propriedade. Aliás, em relação a tal função, acrescenta CARVALHO:

A função ambiental impõe ao proprietário não apenas um dever de abster-se de determinadas atividades (nocivas ambientalmente), como também é fonte de obrigações de fazer no sentido de orientar uma utilização ambientalmente responsável para obtenção de benefícios tanto econômicos como ambientais. Assim, a função ambiental não está no exterior do direito de propriedade, mas compõe seu conteúdo interno, conceitual e constitutivo. ${ }^{12}$

\section{Considerando esse "direito subjetivo público"13 ínsito ao exercício amplo} do direito de propriedade (independentemente do regime ${ }^{14}$ ), a regularização ambiental do imóvel rural é realizada prioritariamente por medidas de manutenção e recuperação ${ }^{15}$ das Áreas de Preservação Permanente ${ }^{16}$, Áreas

10 LAUDARES, Sarita de Alcântara; SILVA, Kmila Gomes da; BORGES, Luís Antônio Coimbra. Cadastro Ambiental Rural: uma análise da nova ferramenta para regularização ambiental do Brasil. Desenvolvimento e Meio Ambiente, Curitiba, v. 31, p.111122, ago. 2014. Disponível em: <http://revistas.ufpr.br/made/article/view/33743>. Acesso em: 28 jul. 2018. p. 117.

11 A área rural consolidada corresponde à "área de imóvel rural com ocupação antrópica preexistente a 22 de julho de 2008 , com edificações, benfeitorias ou atividades agrossilvipastoris, admitida, neste último caso, a adoção do regime de pousio" (artigo $3^{\circ}$, inciso IV, do Código Florestal).

12 CARVALHO, Délton Winter de. Gestão Jurídica Ambiental. São Paulo: Revista dos Tribunais, 2017. p. 28.

13 CARVALHO, Délton Winter de. Gestão Jurídica Ambiental. São Paulo: Revista dos Tribunais, 2017. p. 24.

14 "Este caráter transversal da função ambiental tem sua origem na própria natureza do bem ambiental e na irradiação específica a este de direitos e deveres. O direito ao meio ambiente ecologicamente equilibrado, previsto no art. 225 da Constituição, assinala a dimensão transindividual aos bens ambientais que, apesar de apresentar simultaneidade nas dimensões subjetiva (personalíssima) e objetiva (coletiva), transcende a dicotomia entre público e privado." CARVALHO, Délton Winter de. Gestão Jurídica Ambiental. São Paulo: Revista dos Tribunais, 2017. p. 27.

15 A manutenção corresponde ao emprego de medidas para conservar positivamente o estado como se encontra a área, para que continue nesta mesma situação e/ou melhore. A recuperação é a "restituição de um ecossistema ou de uma população silvestre degradada a uma condição não degradada, que pode ser diferente de sua condição original" (artigo $2^{\circ}$, inciso XIII, da Lei $n^{\circ}$ 9.985/2000). A (c) recomposição ocorre com o plantio de espécies nativas ou a condução da regeneração natural das espécies nativas, podendo esses métodos serem usados conjuntamente. Há ainda a possibilidade do plantio intercalado de espécies exóticas com espécies nativas em até $50 \%$ da área recomposta, mas essa hipótese apenas para pequena propriedade e/ou posse rural familiar (artigo 61-A, §13 e incisos, do Código Florestal). E a (d) regeneração é a implantação das condições necessárias que permitam a vegetação da área lesionada naturalmente refloresça.

16 A Área de Preservação Permanente (APP) é a "área protegida, coberta ou não por vegetação nativa, com a função ambiental de preservar os recursos hídricos, a paisagem, a estabilidade geológica e a biodiversidade, facilitar o fluxo gênico de fauna e flora, proteger o solo e assegurar o bem-estar das populações humanas" (artigo $3^{\circ}$, inciso II, do Código Florestal). 
de Reserva Legal ${ }^{17}$ e Áreas de uso restrito ${ }^{18}$ ou pela adesão, se permitido, à compensação ambiental (artigo $2^{\circ}$, inciso XV, do Decreto $n^{\circ} 7.830 / 2012$ ).

Inclusive, o vigente Código Florestal prescreveu a União Federal, os Estados e o Distrito Federal, o prazo de 1 (um) ano, prorrogável por uma única vez e por igual período, a contar de $2012^{19}$, para implantarem o Programa de Regularização Ambiental (PRA) nos imóveis rurais de suas circunscrições (artigo 59, caput, do Código Florestal combinado com o artigo 10, do Decreto $n^{\circ}$ 7.830/2012). No âmbito estadual e distrital, são requisitos obrigatórios para a implantação do Programa de Regularização Ambiental (PRA):

Art. $4^{\circ}$, do Decreto $\mathrm{n}^{\circ}$ 8.235/2014: I - termo de compromisso, com eficácia de título executivo extrajudicial; II - mecanismos de controle e acompanhamento da recomposição, recuperação, regeneração ou compensação e de integração das informações no Sicar; e III - mecanismos de acompanhamento da suspensão e extinção da punibilidade das infrações de que tratam o $\S 4^{\circ}$ do art. 59 e o art. 60 da Lei $n^{\circ} 12.651$, de 2012, que incluam informações sobre o cumprimento das obrigações firmadas para a suspensão e o encerramento dos processos administrativo e criminal.

O Programa de Regularização Ambiental visa regularizar as Áreas de Preservação Permanente, Áreas de Reserva Legal e Áreas de uso restrito, desmatadas irregularmente até o dia 22/07/2008, com a implementação de medidas de recuperação, seja por meio de recomposição da área, regeneração natural ou pela compensação ambiental (artigo 59, $\$ 4^{\circ}$, do Código Florestal).

Assim, são instrumentos do Programa de Regularização Ambiental (PRA) o Cadastro Ambiental Rural (CAR), o Termo de Compromisso, o projeto de recomposição de áreas degradadas e alteradas e as Cotas de Reserva Ambiental (artigo $9^{\circ}$, incisos I a IV, do Decreto $\mathrm{n}^{\circ} 7.830 / 2012$ ).

17 Em síntese, a Área de Reserva Legal é a cobertura de vegetação nativa que todo imóvel deve destinar em observância aos percentuais explicitados no artigo 12 e incisos do Código Florestal, que variam de $20 \%$ a $80 \%$ conforme o bioma, sem prejuízo das Áreas de Preservação Permanente.

18 As áreas de uso restrito são (i) os pantanais e planícies pantaneiras em que é permitida a exploração ecologicamente sustentável e (ii) as áreas de inclinação entre $25^{\circ}$ e $45^{\circ}$ em que apenas é consentido o manejo florestal sustentável, o exercício de atividades agrossilvipastoris e a manutenção da infraestrutura física para o desenvolvimento dessas atividades (artigos 10 e 11 do Código Florestal).

19 Frisa-se que, após 180 (cento e oitenta) dias contados da publicação do novo códex florestal (2012), a União Federal deverá estabelecer normas de caráter geral para a regulamentação do Programa de Regularização Ambiental, e os Estados e Distrito Federal as normas de caráter específico (artigo $59, \S 1^{\circ}$, do Código Florestal). 


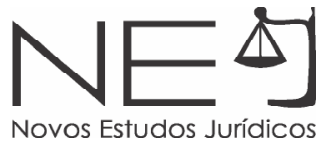

E sobre o Cadastro Ambiental Rural (CAR) que este trabalho se debruçara, haja vista que a efetiva preservação do meio ambiente está intimamente relacionada com a fiscalização pelo Poder Público da regularidade dos imóveis rurais, pois são nestas propriedades que se encontram as principais e maiores áreas verdes do país.

\section{CADASTRO AMBIENTAL RURAL (CAR)}

O Cadastro Ambiental Rural (CAR) é um "registro público eletrônico de âmbito nacional, obrigatório para todos os imóveis rurais, com a finalidade de integrar as informações ambientais das propriedades e posses rurais, compondo base de dados para controle, monitoramento, planejamento ambiental e econômico e combate ao desmatamento" (artigo 29, caput, do Código Florestal) e, a vista disso, viabiliza a correta regularização ambiental do imóvel rural.

LASKOS; CAZALLA e REBOLLAR explicam que o Cadastro Ambiental Rural (CAR) deriva de "ferramentas desenvolvidas desde 2005 relacionadas a metodologias de sensoriamento remoto para identificar os desmatamentos da Amazônia Legal e com os primeiros projetos pilotos de cadastramento na região." 20 Os mesmos autores mencionam os impasses elencados pela doutrina em torno do Cadastro Ambiental Rural (CAR), como se depreende do excerto transcrito a seguir.

Alguns autores, a exemplo de Araújo \& Juras (2012), Camargo (2013) e Laudares et al. (2014), destacam diversos aspectos controversos desse sistema cadastral, como a falta de estrutura dos órgãos ambientais para manter adequadamente o sistema em funcionamento; a falta de segurança jurídica do sistema declaratório proposto pelo CAR quando comparado com o processo de averbação que conta com a anuência prévia do órgão ambiental; a dificuldade de combater as ocupações ilegais baseado em um sistema declaratório em adaptação; a grande quantidade de erros e imprecisões que o sistema do CAR pode provocar, que dificulta ainda mais a fiscalização e o monitoramento por parte dos órgãos ambientais.

20 LASKOS, André Arruda; CAZELLA, Ademir Antônio; REBOLLAR, Paola Beatriz May. O Sistema Nacional de Cadastro Rural: história, limitações atuais e perspectivas para a conservação ambiental e segurança fundiária. Desenvolvimento e Meio Ambiente, Curitiba, v. 36, p.189-199, 30 abr. 2016. Disponível em: <http://revistas.ufpr.br/made/article/view/39124>. Acesso em: $01^{\circ}$ jul. 2018. p. 196. 
Somam-se a isso as dificuldades que os agricultores familiares ainda encontram na adesão ao CAR, principalmente pelo aspecto operacional do cadastro e a precariedade dos serviços de internet em municípios pequenos e médios do país. A complexidade do problema aumenta para os povos e comunidades tradicionais, onde a informação não chega tão facilmente e as ações de sindicatos e órgãos públicos municipais quase sempre são ineficientes nesse campo do conhecimento. Ademais, o novo código não dispõe claramente sobre a aplicação do CAR nas diferentes situações territoriais. ${ }^{21}$

Não obstante as críticas ao sistema, inegável que a sua implantação está evoluindo e alcançando grande parte do território nacional, como se pode verificar pelo Boletim Informativo do CAR, elaborado pelo Serviço Florestal Brasileiro (SFB). Conforme avaliação realizada até o dia 30 de junho de 2018, foi averiguado que há no Brasil 397.836.864 hectares passíveis de cadastro, 455.469.947 hectares cadastrados, 5.205.983 imóveis cadastrados e um percentual total de área cadastrada acima de $100 \%{ }^{2223}$.

Mais da metade das regiões do país alcançaram taxa acima de 100\% de área cadastrada. Como se depreende da região Sul, que possui 41,7 milhões de hectares de área cadastrável, 44,8 milhões de hectares cadastrados e 1.300.776 imóveis cadastrados; a região Sudeste, com 56,3 milhões de hectares de área cadastrável, 67,8 milhões de hectares cadastrados e 1.165 .533 imóveis cadastrados; e a região Norte, com 93,7 milhões de hectares de área cadastrável, 139,2 milhões de hectares cadastrados e 702.797 imóveis cadastrados. E as demais regiões logo superarão as expectativas, dado que a região Nordeste possui 76,1 milhões de hectares de área cadastrável, 75,4 milhões de hectares cadastrados e 1.621 .605 imóveis cadastrados, apresentando uma taxa de 99,1\% de área cadastrada; e a região Centro-oeste, 129,9 milhões de hectares de área cadastrável, 128,3 milhões de hectares cadastrados, e 415.272 imóveis cadastrados, com taxa de 98,8\%

21 LASKOS, André Arruda; CAZELLA, Ademir Antônio; REBOLLAR, Paola Beatriz May. O Sistema Nacional de Cadastro Rural: história, limitações atuais e perspectivas para a conservação ambiental e segurança fundiária. Desenvolvimento e Meio Ambiente, Curitiba, v. 36, p.189-199, 30 abr. 2016. Disponível em: <http://revistas.ufpr.br/made/article/view/39124>. Acesso em: $01^{\circ}$ jul. 2018. p. 197.

22 Acredita-se que a percentagem acima de 100\% em referência no Boletim Informativo do CAR tem como parâmetro uma estimativa interna feita pelos pesquisadores e técnicos de uma área total que se quer alcançar, em um determinado período. De maneira que se o projeto tencionava cadastrar no sistema eletrônico 1.000 hectares, no prazo de três meses, e ao contabilizar os dados verificou-se uma área maior que essa, então foram ultrapassadas as expectativas - ou seja, foi acima de $100 \%$.

23 SFB - SERVIÇO FLORESTAL BRASILEIRO. Cadastro Ambiental Rural (CAR): Boletim Informativo, dados até 30 de junho de 2018. Brasília, 30 jun. 2018. Disponível em: < http://www.florestal.gov.br/documentos/car/boletim-do-car/3735-boletiminformativo-julho-de-2018/file>. Acesso em: 04 ago. 2018. 


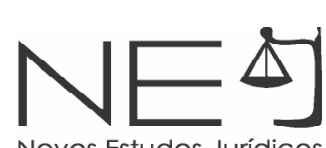

de área cadastrada. ${ }^{24}$ Ademais, conforme o Módulo de Relatórios do próprio Serviço Florestal Brasileiro (SFB), em 30 de junho de 2018, foram contabilizados 469.613.648,2011 hectares de área cadastrada no país, com o cadastro de 4.474.858 imóveis rurais. Deste total de imóveis rurais cadastrados, 4.116.173 correspondem aos da classe de 0 a 4 Módulos Fiscais ${ }^{25}$ (MF), perfazendo 145,9 milhões de hectares; 263.139 da classe de 4 a 15 Módulos Fiscais e 86,0 milhões de hectares; 95.546 da classe maior que 15 Módulos Fiscais e 237,5 milhões de hectares. $^{26}$

Não obstante os números do Boletim Informativo do CAR divergirem ${ }^{27}$ com os apresentados no Módulo de Relatório do CAR, ambos denotam dados positivos quanto à implantação do cadastramento em todo o Brasil.

De acordo com o artigo $29, \S 1^{\circ}$, do Código Florestal combinado com o teor do artigo $5^{\circ}$, do Decreto $n^{\circ} 7.830 / 2012$, as informações elementares para se realizar a inscrição, frisa-se obrigatória, no Cadastro Ambiental Rural (CAR), preferencialmente, no órgão estadual ou municipal são: os dados do proprietário, possuidor rural ou responsável direto pelo imóvel rural e os respectivos comprovantes de posse e/ou propriedade; a planta georreferenciada do perímetro do imóvel, das áreas de interesse social e das áreas de utilidade pública, constando informações sobre a localização dos remanescentes de

24 SFB - SERVIÇO FLORESTAL BRASILEIRO. Cadastro Ambiental Rural (CAR): Boletim Informativo, dados até 30 de junho de 2018. Brasília, 30 jun. 2018. Disponível em: < http://www.florestal.gov.br/documentos/car/boletim-do-car/3735-boletiminformativo-julho-de-2018/file>. Acesso em: 04 ago. 2018.

25 O Módulo Fiscal é uma unidade de medida, em hectares, definida pelo INCRA para cada município em observância aos requisitos: "(a) o tipo de exploração predominante no município (hortifrutigranjeira, cultura permanente, cultura temporária, pecuária ou florestal); (b) a renda obtida no tipo de exploração predominante; (c) outras explorações existentes no município que, embora não predominantes, sejam expressivas em função da renda ou da área utilizada; (d) o conceito de 'propriedade familiar'." EMBRAPA - EMPRESABRASILEIRA DE PESQUISAAGROPECUÁRIA. Módulos fiscais. Brasília: [2018?]. Disponível em: <https://www.embrapa.br/codigo-florestal/area-de-reserva-legal-arl/modulo-fiscal>. Acesso em: 11 ago. 2017. Conforme a Lei $n^{\circ} 8.629 / 1993$ (art. $4^{\circ}$, incisos II, alínea a; inciso III, alínea a), a pequena propriedade rural é aquela que possui área de até 4 (quatro) módulos fiscais e a média propriedade, área superior a 4 (quatro) e inferior a 15 (quinze) módulos fiscais; logo, acima de 15 módulos fiscais considera-se grande propriedade.

26 SFB - SERVIÇO FLORESTAL BRASILEIRO. Módulos de Relatórios. In: Cadastro Ambiental Rural. Brasília, 30 jun. 2018. Disponível em: <http://www.florestal.gov.br/modulo-de-relatorios>. Acesso em: 04 ago. 2018.

27 O próprio Serviço Florestal Brasileiro - SFB explica que os dados do Módulo de Relatórios podem ser diferentes do Boletim Informativo do CAR em razão dos fatores a seguir: "a. metodologia de elaboração do Boletim Informativo do CAR, que considera o número de famílias registradas nos imóveis rurais de assentamentos da reforma agrária como o número de imóveis declarados na área de um assentamento, ao passo que o Módulo Público de Relatórios apresenta somente o número de assentamentos inscritos no CAR; b. ações de monitoramento da base de dados do SICAR, que exclui cadastros evidentemente falsos da contabilização oficial do Boletim; c. informações declaradas pelos estados que possuem sistemas próprios de cadastramento cujos dados ainda não foram migrados ou estão em fase de migração ao SICAR; d. horários divergentes de fechamento de consultas realizadas. "SFB - SERVIÇO FLORESTAL BRASILEIRO. Módulos de Relatórios. In: Cadastro Ambiental Rural. Brasília, 30 jun. 2018. Disponível em: <http://www.florestal.gov.br/modulo-de-relatorios>. Acesso em: 04 ago. 2018. 
vegetação nativa ${ }^{28}$, Áreas de Preservação Permanente, Áreas de Uso Restrito, áreas consolidadas e das Áreas de Reserva Legal.

O artigo $18, \S 4^{\circ}$, do Código Florestal prescreve que o registro da área de Reserva Legal no Cadastro Ambiental Rural (CAR) desobriga o proprietário/ possuidor de averbá-la no Cartório de Registro de Imóveis (CRI). Mas caso o proprietário/possuidor ainda assim deseje realizar a averbação, terá direito à gratuidade do ato, desde que o faça no período entre a data da publicação do Código Florestal e o registro no Cadastro Ambiental Rural (CAR).

Aliás, considerando os dados já organizados pelo Cartório de Registro de Imóveis (CRI), a legislação florestal prescreve que apenas serão dispensadas as informações relativas à Área de Reserva Legal, nos moldes do artigo 29, §1, inciso III, do Código Florestal ${ }^{29}$, caso essa área já tenha sido averbada na matrícula do imóvel. Nesta situação, o proprietário deverá apresentar ao órgão ambiental competente a certidão de registro de imóveis com a averbação da reserva e o posseiro o Termo de Compromisso firmado (artigo 30, caput e parágrafo único, do Código Floresta ${ }^{30}$ ).

E no artigo 29, $2^{\circ}$, do Código Florestal, a norma é clara quanto à impossibilidade de o Cadastro Ambiental Rural (CAR) poder ser considerado como título de reconhecimento do direito de propriedade ou posse. Logo, o fato de o imóvel rural estar cadastrado neste sistema virtual não elimina as obrigações do proprietário/possuidor dispostas no artigo $2^{\circ}$ da Lei $n^{\circ} 10.267 / 2001^{31}$, relacionado com o Cadastro Nacional de Imóveis Rurais (CNIR).

Urge anotar a inteligência do legislador infraconstitucional e da sistemática do Cadastro Ambiental Rural (CAR) ao estipular várias condicionantes interligadas

28 Conforme o artigo $2^{\circ}$, inciso IV, do Decreto $n^{\circ} 7.830 / 2012$, área de remanescente de vegetação nativa é a "área com vegetação nativa em estágio primário ou secundário avançado de regeneração. "

29 Código Florestal, artigo $29, \S 1^{\circ}$, inciso III: "identificação do imóvel por meio de planta e memorial descritivo, contendo a indicação das coordenadas geográficas com pelo menos um ponto de amarração do perímetro do imóvel, informando a localização dos remanescentes de vegetação nativa, das Áreas de Preservação Permanente, das Áreas de Uso Restrito, das áreas consolidadas e, caso existente, também da localização da Reserva Legal. "

30 Código Florestal, artigo 30: "Nos casos em que a Reserva Legal já tenha sido averbada na matrícula do imóvel e em que essa averbação identifique o perímetro e a localização da reserva, o proprietário não será obrigado a fornecer ao órgão ambiental as informações relativas à Reserva Legal previstas no inciso III do $\$ 1^{\circ}$ do art. 29 . Parágrafo único. Para que o proprietário se desobrigue nos termos do caput, deverá apresentar ao órgão ambiental competente a certidão de registro de imóveis onde conste a averbação da Reserva Legal ou termo de compromisso já firmado nos casos de posse."

31 artigo $2^{\circ}$ da Lei $n^{\circ} 10.267 / 2001$ dispõe sobre as alterações nos textos dos artigos $1^{\circ}, 2^{\circ}$ e $8^{\circ}$ da Lei $n^{\circ} 5.868 / 1972$, que cria o Sistema Nacional de Cadastro Rural. 


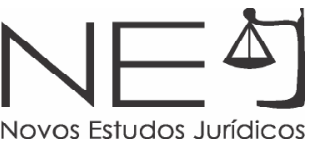

com o cadastramento do imóvel rural, para que o proprietário/possuidor possa fruir de alguns benefícios, programas e autorizações, listados a seguir.

O registro da Reserva Legal no CAR desobriga a averbação no Cartório de Registro de Imóveis; Acesso ao Programa de Apoio e Incentivo à Conservação do Meio Ambiente e aos Programas de Regularização Ambiental - PRA;

Obtenção de crédito agrícola, em todas as suas modalidades, com taxas de juros menores, bem como limites e prazos maiores que o praticado no mercado, em especial após 31 de dezembro de 2017, quando o CAR será pré-requisito para o acesso a crédito;

Contratação do seguro agrícola em condições melhores que as praticadas no mercado;

Geração de créditos tributários por meio da dedução das Áreas de Preservação Permanente, de RL e de uso restrito da base de cálculo do Imposto sobre a Propriedade Territorial Rural - ITR;

Linhas de financiamento para atender iniciativas de preservação voluntária de vegetação nativa, proteção de espécies da flora nativa ameaçadas de extinção, manejo florestal e agroflorestal sustentável realizados na propriedade ou posse rural, ou recuperação de áreas degradadas;

Isenção de impostos para os principais insumos e equipamentos, tais como: fio de arame, postes de madeira tratada, bombas d'água, trado de perfuração do solo, dentre outros utilizados para os processos de recuperação e manutenção das Áreas de Preservação Permanente, de Reserva Legal e de uso restrito;

Suspensão de sanções e novas autuações em função de infrações administrativas por supressão irregular de vegetação em áreas de preservação permanente, de Reserva Legal e de uso restrito, cometidas até 22/07/2008, e suspensão da punibilidade dos crimes previstos nos arts. 38, 39 e 48 da Lei de crimes ambientais (Lei n 9.605/1998) associados a essas áreas; 
Condição para autorização da prática de aquicultura e infraestrutura a ela associada nos imóveis rurais com até 15 (quinze) módulos rurais, localizados em áreas de preservação permanente;

Condição para autorização de supressão de floresta ou outras formas de vegetação nativa no imóvel rural;

Condição para aprovação da localização da Reserva Legal;

Condição para cômputo das Áreas de Preservação Permanente no cálculo da Reserva Legal do imóvel; Condição para autorização da exploração econômica da Reserva Legal mediante manejo sustentável;

Condição para constituição de Servidão Ambiental e Cota de Reserva Ambiental, e acesso aos mecanismos de compensação da Reserva Legal;

Condição para autorização de intervenção e supressão de vegetação em Áreas de Preservação Permanente e de Reserva Legal para atividades de baixo impacto ambiental;

Condição para autorização da continuidade das atividades agrossilvipastoris, de ecoturismo e de turismo rural em áreas rurais consolidadas até em 22 de julho de 2008 localizadas em Áreas de Preservação Permanente e Reserva Legal. ${ }^{32}$

Destarte, com tais estratégias de indução legal aliadas aos instrumentos econômicos, o proprietário/possuidor torna-se mais compelido ao cadastramento. Implicando diretamente na real adesão da população ao sistema virtual de regularização ambiental e, consequentemente, na efetivação da catalogação das áreas verdes para fins de proteção do meio ambiente nacional e, frisa-se, de interesse intergeracional.

A inscrição no Cadastro Ambiental Rural (CAR) tem natureza declaratória e permanente. Logo, além da atualização periódica do cadastro, quaisquer

32 SICAR - SISTEMA DE CADASTRO AMBIENTAL RURAL. Sobre: O que é o CAR?. [2018?]. Disponível em: <http://www.car. gov.br/\#/sobre>. Acesso em: 28 jul. 2018. 


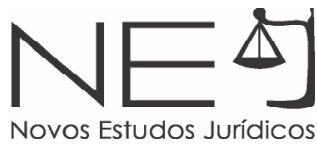

alterações de dados constantes no mesmo, sobretudo de natureza dominial ou possessória, devem ser comunicadas pelo proprietário, possuidor ou representante legalmente constituído ao órgão ambiental competente (artigo $6^{\circ}$, caput e $\S \S 3^{\circ}$ e $4^{\circ}$, do Decreto $\left.n^{\circ} 7.830 / 2012\right)$.

Não se deve esquecer de que "as informações são de responsabilidade do declarante, que incorrerá em sanções penais e administrativas, sem prejuízo de outras previstas na legislação, quando total ou parcialmente falsas, enganosas ou omissas" (artigo 60, $§ 1^{\circ}$, do Decreto $n^{\circ} 7.830 / 2012$ ).

Para compreender o procedimento da inscrição no Cadastro Ambiental Rural (CAR) é necessário, primeiramente, articular que o Sistema de Cadastro Ambiental Rural (SICAR) é o sistema eletrônico de âmbito nacional, destinado à integração e ao gerenciamento de informações ambientais dos imóveis rurais pátrios. Ele foi criado pelo Decreto $n^{\circ} 7.830 / 2012$ e tem como principais objetivos:

Decreto $n^{\circ}$ 7.830/2012, Art. $3^{\circ}$. I - receber, gerenciar e integrar os dados do CAR de todos os entes federativos; II - cadastrar e controlar as informações dos imóveis rurais, referentes a seu perímetro e localização, aos remanescentes de vegetação nativa, às áreas de interesse social, às áreas de utilidade pública, às Áreas de Preservação Permanente, às Áreas de Uso Restrito, às áreas consolidadas e às Reservas Legais; III - monitorar a manutenção, a recomposição, a regeneração, a compensação e a supressão da vegetação nativa e da cobertura vegetal nas áreas de Preservação Permanente, de Uso Restrito, e de Reserva Legal, no interior dos imóveis rurais; IV - promover o planejamento ambiental e econômico do uso do solo e conservação ambiental no território nacional; e V - disponibilizar informações de natureza pública sobre a regularização ambiental dos imóveis rurais em território nacional, na Internet.

O sítio eletrônico do Sistema de Cadastro Ambiental Rural (SICAR) é www.car. gov.br. Nele há plataformas para inscrição, consulta, retificação e acompanhamento da situação da regularização ambiental do imóvel rural, assim como informações amplas sobre o Cadastro Ambiental Rural (CAR), dados estatísticos e imagens do mapeamento das propriedades e posses rurais disponibilizados pelo Ministério do Meio Ambiente (MMA). 
Frisa-se que os órgãos integrantes do Sistema Nacional de Informações sobre o Meio Ambiente (SINIMA) - ou melhor dizendo, do Sistema Nacional do Meio Ambiente- SISNAMA - devem disponibilizar, em seus respectivos sites, o link do sítio eletrônico do Sistema de Cadastro Ambiental Rural (SICAR), para maximizar a divulgação de informações sobre este instrumento (artigo $3^{\circ}, \S \S 1^{\circ}$ e $4^{\circ}$, do Decreto $n^{\circ} 7.830 / 2012$ )

O Sistema de Cadastro Ambiental Rural (CAR) é gerido pelos órgãos ambientais estaduais e distritais. Este sistema organiza e integra todas essas informações que irão "subsidiar políticas, programas, projetos e atividades de controle, monitoramento, planejamento ambiental e econômico e combate ao desmatamento ilegal." 33

Por isso, "os entes federativos que já disponham de sistema para o cadastramento de imóveis rurais deverão integrar sua base de dados ao Sistema de Cadastro Ambiental Rural - SICAR, nos termos do inciso VIII do caput do art. $8^{\circ}$ e do inciso VIII do caput do art. $9^{\circ}$ da Lei Complementar $n^{\circ} 140$, de 8 de dezembro de 2011", conforme o art. $4^{\circ}$ do Decreto $n^{\circ} 7.830 / 2012$. Em relação a este quadro nacional sobre as bases estaduais de cadastramento virtual das propriedades rurais, tem-se que:

Atualmente, 05 (cinco) estados possuem sistemas eletrônicos próprios: Bahia, Espírito Santo, Mato Grosso do Sul, São Paulo e Tocantins. Outros 06 (seis) estados utilizam aplicações (sub-módulos do SICAR) desenvolvidas pelo governo federal, mas instaladas em infraestruturas de Tecnologia da Informação estaduais, com bancos de dados dos próprios estados. São estes: Acre, Mato Grosso, Minas Gerais, Pará, Rio Grande do Sul e Rondônia. No caso desses 11 (onze) estados, o acesso aos sistemas de cadastramento e regularização deve ser obtido diretamente na página oficial dos estados na internet. A emissão do Recibo de Inscrição pelo SICAR não será imediata, pois dependerá da integração entre sistemas e da transmissão dos dados para o SICAR. Os demais estados que utilizam as aplicações do SICAR e a infraestrutura de Tecnologia da Informação provida pelo Serviço Florestal Brasileiro e pelo Ministério de Meio Ambiente são: Alagoas, Amapá, Amazonas, Ceará, Distrito Federal, Goiás, Maranhão, Paraíba, Paraná, Pernambuco, Piauí, Rio de Janeiro, Rio Grande do Norte, Roraima, Santa Catarina e Sergipe. ${ }^{34}$

33 SICAR - SISTEMA DE CADASTRO AMBIENTAL RURAL. Sobre: O que é o CAR?. [2018?]. Disponível em: <http://www.car. gov.br/\#/sobre>. Acesso em: 28 jul. 2018.

34 SICAR - SISTEMA DE CADASTRO AMBIENTAL RURAL. Sobre: O que é o CAR?. [2018?]. Disponível em: <http://www.car. gov.br/\#/sobre>. Acesso em: 28 jul. 2018. 
E para não obstar a implementação do Cadastro Ambiental Rural (CAR) nos entes federativos que não disponham de sistema para o cadastramento de imóveis rurais, o artigo $3^{\circ}, \S 2^{\circ}$, do Decreto $n^{\circ} 7.830 / 2012$, estipulou que eles "poderão utilizar o módulo de cadastro ambiental rural, disponível no SICAR, por meio de instrumento de cooperação com o Ministério do Meio Ambiente. "

Ademais, nota-se que os órgãos ambientais competentes possuem mais uma ferramenta para a catalogação da natureza verde, pois "poderão desenvolver módulos complementares para atender as peculiaridades locais, desde que sejam compatíveis com o SICAR e observem os Padrões de Interoperabilidade de Governo Eletrônico - e-PING, em linguagem e mecanismos de gestão de dados", de acordo com o artigo $3^{\circ}$, $3^{\circ}$, do Decreto $n^{\circ} 7.830 / 2012$.

\subsection{REQUERIMENTO DE INSCRIÇÃO}

O requerimento de inscrição no Cadastro Ambiental Rural (CAR) é gratuito e de total responsabilidade do proprietário/possuidor. O pedido é composto por 4 (quatro) etapas, são elas: (a) módulo de cadastramento, (b) protocolo, (c) envio do arquivo ".car" e (d) recibo.

No (a) módulo de cadastramento, os entes federativos que não possuam sistema próprio de cadastramento de imóvel rural deverão acessar o portal eletrônico do Sistema de Cadastro Ambiental Rural (SICAR), clicar na aba Módulo de Cadastro, localizar o Estado que pertence o imóvel e baixar o programa.

Após identificar o tipo de propriedade a ser cadastrada, será realizada a inscrição com todas as informações ${ }^{35}$ discriminadas na legislação pertinente e respondido um questionário complementar sobre a situação do imóvel. Analisando a Instrução Normativa $n^{\circ}$ 2/2014 do Ministério do Meio Ambiente, LEHFELD, CARVALHO e BALBIM ressaltam que:

A Instrução Normativa $n^{\circ}$ 2/2014 do Ministério do Meio Ambiente tratou de importantes regras voltadas à inscrição no CAR em situações

35 Em relação à apresentação da planta ou do memorial descritivo do imóvel rural, este deverá ser elaborado, assinado e instruído com a Anotação de Responsabilidade Técnica por profissional habilitado e inscrito no Conselho Regional de Engenharia e Agronomia (CREA) - artigo $1^{\circ}$ da Lei $n^{\circ} 6.496 / 1977$. O proprietário/possuidor deverá patrocinar os serviços deste profissional, salvo nos casos das propriedades salvaguardadas pelo procedimento simplificado de inscrição no Cadastro Ambiental Rural (CAR), dado que poderão receber auxílio do Poder Público (artigo 30 da IN-MMA n² 2/2014). 
peculiares: a) havendo mais de um proprietário ou possuidor será feita apenas uma inscrição com indicação da identificação de todos os proprietários ou possuidores; b) se o proprietário ou possuidor dispõe de mais de uma propriedade ou posse em área contínua, deverá efetuar uma única inscrição para esses imóveis (e o cumprimento do percentual mínimo da $R L$, bem como a definição da faixa de Área de Preservação Permanente levará em consideração a totalidade das áreas); c) se o imóvel estiver em mais de um ente federado, a inscrição será feita no ente em que está o maior percentual da área, em hectare [conforme artigos 31, 32 e 33 da própria Instrução Normativa]. ${ }^{36}$

Frisa-se que, durante a inscrição do imóvel rural no Cadastro Ambiental Rural (CAR), o proprietário/possuidor deverá informar os passivos ambientais existentes na propriedade. E se, por um lado, o proprietário/possuidor não poderá ser autuado, por outro, o imóvel será incluso no Programa de Regularização Ambiental (PRA) e se comprometerá a adimplir as condicionantes de regularização ambiental.

Não obstante a Área de Reserva Legal declarada pelo proprietário/possuidor no ato de inscrição no Cadastro Ambiental Rural (CAR) prescindir de aprovação do órgão estadual do Sistema Nacional do Meio Ambiente (SISNAMA) - artigo 47 da IN-MMA n²/2014) -, a compensação já realizada na Área de Reserva Legal poderá ser utilizada para fins de regularização do imóvel nos moldes dos artigos 28 e 29, da IN-MMA n 02/2014. Além disto, as áreas excedentes de Área de Reserva Legal também poderão ser informadas durante a inscrição no Cadastro Ambiental Rural (CAR), para serem destinadas à compensação ambiental (artigo 38, da IN-MMA n 02/2014). O órgão ambiental competente está autorizado a qualquer tempo realizar vistorias in loco para averiguar a veracidade das informações retratadas no ato de inscrição do Cadastro Ambiental Rural (CAR) e para acompanhar os compromissos assumidos, podendo os documentos solicitados serem encaminhados via eletrônica (artigos $7^{\circ}$, §§ $3^{\circ}$ e $4^{\circ}$, da INMMA n02/2014).

Detectada alguma pendência e/ou inconsistência nas informações e nos documentos apresentados pelo proprietário/possuidor, o órgão ambiental

36 LEHFELD, Lucas de Souza; CARVALHO, Nathan Castelo Branco de; BALBIM, Leonardo Nassif. Código Florestal comentado e anotado: artigo por artigo. 3. ed. São Paulo: Método, 2015. p. 196. 


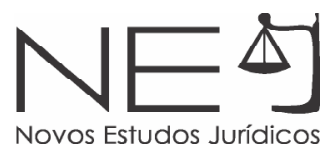

responsável deverá notificá-lo uma única vez para que retifique ${ }^{37}$ e/ou esclareça as dubiedades, sob pena de ter cancelada a inscrição no Cadastro Ambiental Rural (CAR), segundo o artigo $7^{\circ}$, caput e $\S 1^{\circ}$, da IN-MMA nº 02/2014.

Outrossim, dispõe o artigo $7^{\circ}, \S 2^{\circ}$, desta mesma Instrução Normativa que: "Enquanto não houver manifestação do órgão competente acerca de pendências ou inconsistências nas informações declaradas e nos documentos apresentados para a inscrição no CAR, será considerada efetivada a inscrição do imóvel rural no CAR, para todos os fins previstos em lei."

Estando todas as informações corretas, os dados serão gravados e o cadastro finalizado, sendo gerado um (b) Protocolo de Preenchimento para Inscrição no Cadastro Ambiental Rural (CAR) e um arquivo digital com extensão ".car". Finda a gravação, o arquivo com extensão ".car" deverá ser (c) enviado ao site do Sistema de Cadastro Ambiental Rural (SICAR) na aba Módulo de Cadastro, que gerará um (d) Recibo de Inscrição do Imóvel Rural no Cadastro Ambiental Rural (CAR). Este Recibo é o documento que confirma o cadastramento do imóvel nos moldes do Código Florestal, e que "não substitui qualquer licença ou autorização ambiental para exploração florestal ou supressão de vegetação, como também não dispensa as autorizações cabíveis para o exercício da atividade econômica no imóvel." ${ }^{38}$

Urge salientar que a inscrição no Cadastro Ambiental Rural (CAR) é obrigatória para todos os imóveis rurais, porém algumas propriedades poderão realizar o registro simplificado com a apresentação das seguintes informações: identificação do proprietário ou possuidor rural do imóvel; comprovação da propriedade ou posse; e croqui, indicando a área do imóvel, as Áreas de Preservação Permanente, as Áreas de Reserva Legal, de servidões administrativas, consolidadas e as de uso restrito, quando houver (artigo 14, da IN-IBAMA n²/2014).

37 "Após gravados, os cadastros não podem ser editados. Neste caso, se o arquivo com extensão ".car" não tiver sido enviado ao SICAR, com a consequente geração do Recibo de Inscrição, deverá ser preenchido um novo cadastro, em que todas as informações deverão ser novamente declaradas. Caso contrário, eventuais correções poderão ser realizadas acessando a opção "Retificar" no Módulo de Cadastro, aproveitando as informações já declaradas por meio da utilização do arquivo com extensão ".car" já enviado para o SICAR, desde que o cadastro não esteja sendo analisado pelo órgão competente." (SICAR, [2018?])

38 SICAR - SISTEMA DE CADASTRO AMBIENTAL RURAL. Sobre: O que é o CAR?. [2018?]. Disponível em: <http://www.car. gov.br/\#/sobre>. Acesso em: 28 jul. 2018. 
Conforme o artigo $8^{\circ}, 3^{\circ}$, do Decreto $n^{\circ} 7.830 / 2012$, gozarão dessas benesses as pequenas propriedades ou posses rurais familiares com até 4 (quatro) módulos fiscais e que desenvolvam atividades agrossilvipastoris, terras indígenas demarcadas e demais áreas tituladas de povos e comunidades tradicionais que façam uso coletivo do seu território.

Tais proprietários ainda têm a opção de não patrocinarem as medidas para a captação das coordenadas geográficas do imóvel rural se aceitarem o auxílio do órgão competente do Sistema Nacional do Meio Ambiente (SISNAMA) e ter os serviços de prestação de apoio técnico e jurídico pelo Poder Público (artigo $8^{\circ}, \S 2^{\circ}$, do Decreto $\left.n^{\circ} 7.830 / 2012\right)$; além do mais, o registro da Área de Reserva Legal do imóvel é gratuito (artigo 53, parágrafo único, do Código Florestal).

\subsection{POSTERGAÇÃO INDEVIDA}

O artigo 29, $3^{\circ}$, do Código Florestal estipulou o prazo de 1 (um) ano, prorrogável, uma única vez e porigual período, por ato do Chefe do Poder Executivo, para que os proprietários/possuidores providenciassem o cadastramento dos imóveis rurais no Cadastro Ambiental Rural (CAR).

Todavia, inexplicavelmente, o Ministério do Meio Ambiente (MMA) apenas expediu em 6 de maio de 2014 a Instrução Normativa $n^{\circ}$ 2, que prescreve os procedimentos gerais para a implantação do Cadastro Ambiental Rural e seu respectivo sistema (CAR-SICAR). Tal situação ocasionou um vácuo de aproximadamente 3 (três) anos para o início do cadastramento dos imóveis rurais no sistema virtual de catalogação das áreas verdes especialmente protegidas. Portanto, a data desta instrução normativa é que realmente representa o marco inicial da contagem do prazo para os imóveis serem incorporados ao Cadastro Ambiental Rural (CAR), ou seja, até maio de 2015. Não obstante esse interregno temporal e a prorrogação do prazo até maio de 2016, a Lei no 13.295/2016, alterando a redação do artigo 29 do Código Florestal, autorizou nova prorrogação do prazo para a inscrição dos imóveis rurais no Cadastro Ambiental Rural (CAR) até o dia 31 de dezembro de 2017, prorrogável por mais 1 (um) ano. 


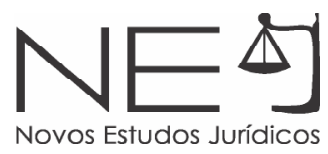

Outrossim, novamente o prazo foi prorrogado, desta vez via Decreto presidencial no 9.257, de 29 de dezembro de 2017, autorizando o cadastramento dos imóveis rurais no CAR/SICAR até o dia 31 de maio de 2018.

Não se olvida da necessidade de um período de adaptação aos proprietários/possuidores de imóveis rurais no Brasil para se adequarem às novas regras previstas no Código Florestal, como o cadastramento no Cadastro Ambiental Rural (CAR). Ainda mais pelo fato de que o exercício pleno do direito de propriedade está diretamente relacionado com a regularidade ambiental (função ambiental da propriedade).

Todavia, este período de adaptação das regras deve ser razoável e, no caso de serem realizadas prorrogações, que elas sejam devidamente justificadas e limitadas, a fim de que a segurança jurídica impere nas relações dos que estão regularizados, em processo de regularização ou simplesmente não querem se regularizar.

As reflexões alhures se justificam tendo em vista os projetos de Lei em tramitação no Senado Federal e na Câmara dos Deputados, que tencionam postergar o prazo final para a inscrição dos imóveis rurais no Cadastro Ambiental Rural (CAR) e a mais recente prorrogação feita pelo Presidente da República.

No Senado Federal, o Projeto de Lei $287 / 2015^{39}$ visa alterar o artigo 29, $\S 3^{\circ}$, do Código Florestal, a fim de estender o prazo de inscrição das propriedades e posses rurais no Cadastro Ambiental Rural (CAR) de 1 (um) para 3 (três) anos, prorrogável uma única vez. Embora o projeto de lei tenha sido enviado em 2015 e, por conseguinte, o prazo à época pretendido para ser prorrogado já até foi ultrapassado, o texto ainda pode ser alterado e atualizados os marcos temporais. Logo a preocupação permanece.

E na Câmara dos Deputados está em tramitação o Projeto de Lei 4550/201640, que visa que a inscrição no Cadastro Ambiental Rural (CAR) seja requerida "até

39 De autoria do Senador rondoniense Romero Jucá, filiado ao Partido da Social Democracia Brasileira (PSDB), o Projeto de Lei 287/2015 pretende a aprovação do seguinte texto ao §3º artigo 29, do Código Florestal: "A inscrição no CAR será obrigatória para todas as propriedades e posses rurais, devendo ser requerida no prazo de 3 (três) anos contados da sua implantação, prorrogável, uma única vez, por um ano, por ato do Chefe do Poder Executivo." (NR).

40 De autoria do Deputado Federal Heitor José Schuch, filiado ao Partido Socialista Brasileiro (PSB). 
Novos Estudos Jurídicos

o dia 5 de maio de 2018, prorrogável por ato do Chefe do Poder Executivo." As mesmas observações em relação à atualização do texto, sobretudo dos marcos finais, expressas para o Projeto de Lei $287 / 2015$ se aplicam a este projeto. Mas aqui se sublinha quanto essa possibilidade de prorrogação é ilimitada pelo Presidente da República, o que, de certo modo, vem sendo feito, mas não significa que deve ser mantido.

E o governo federal, via Decreto presidencial $n^{\circ}$ 9.395, de 30 de maio de 2018, prorrogou a prorrogação por ele mesmo prorrogada no Decreto no 9.257/2017. Ou seja, até o momento, o prazo final para as propriedades rurais serem cadastradas no Cadastro Ambiental Rural (CAR) é até o dia 31 de dezembro de 2018. Neste contexto, é válido o questionamento realizado por BARBOSA e LEHFELD: "O Cadastro Ambiental Rural (CAR) e a sua efetivação: até quando será postergada?"41

Aliás, compatibiliza com as consternações anteriores a Rede Observatório do Código Florestal, que lista algumas das inúmeras consequências negativas que a autorização da prorrogação do prazo para inscrição dos imóveis rurais no Cadastro Ambiental Rural (CAR) poderá causar, como:

O reforço da tese de ineficiência do poder público;

O descrédito da legislação vigente;

Perda de credibilidade no mercado global de commodities agrícolas;

A premiação ao descumprimento legal de prazos e obrigações já estabelecidos;

O desrespeito aos mais de 4 milhões de produtores rurais já inscritos no CAR; 


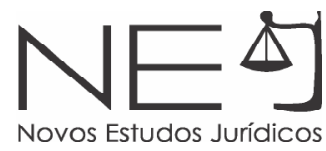

A desmobilização do processo de validação e monitoramento do CAR e;

Principalmente, um potencial aumento do desmatamento - a exemplo do ocorrido em $2016 .{ }^{42}$

Em outras tintas, depreende-se que as prorrogações para a data limite de inscrição dos imóveis rurais no Cadastro Ambiental Rural (CAR) prejudica a segurança jurídica e a eficiência do Poder Público para a implantação e implementação das regras ambientais, sobretudo àquelas constantes no Código Florestal de 2012. Também obstaculiza a fiscalização estatal otimizada - caso este instrumento estivesse totalmente implementado - quanto à devida proteção e manutenção da natureza verde pelos proprietários/possuidores rurais, dos desmatamentos realizados e os que estão em vias de serem feitos.

Ademais, desrespeita aqueles proprietários/possuidores rurais que já realizarão o cadastro e favorece os que não cumprem os prazos legais para a regularização do imóvel rural. Neste ponto urge tecer alguns comentários sobre o artigo 78-A, do Código Florestal, alterado pela Lei no 13.295/2016, a seguir transcrito.

Art. 78-A. Após 31 de dezembro de 2017, as instituições financeiras só concederão crédito agrícola, em qualquer de suas modalidades, para proprietários de imóveis rurais que estejam inscritos no CAR. Parágrafo único. O prazo de que trata este artigo será prorrogado em observância aos novos prazos de que trata o § $3^{\circ}$ do art. 29.

Depreende-se que a lei florestal tencionou valorizar aqueles que dentro do prazo se cadastraram no Cadastro Ambiental Rural (CAR). De tal modo que, findo o prazo final para a adesão a esta medida (geral), as instituições financeiras não poderiam conceder crédito agrícola ${ }^{43}$ aos que não se encontrassem devidamente cadastrados. Todavia, o parágrafo único do artigo 78-A do Código Florestal

42 OBSERVATÓRIO DO CÓDIGO FLORESTAL. O prazo para cadastramento no CAR não deve ser prorrogado uma terceira vez indistintamente. Brasília, 07 jul. 2017. Disponível em: <http://www.observatorioflorestal.org.br/noticia/o-prazo-paracadastramento-no-car-nao-deve-ser-prorrogado-uma-terceira-vez-indistintamente>. Acesso em: 11 jul. 2018.

43 Urge destacar que o Banco Central menciona como crédito rural os recursos que abrangem custeio, investimento ou comercialização de produtos relacionados com a produção agrícola (agricultura ou pecuário). Inclusive disponibiliza o Manual de Crédito Rural (MCR), o qual estabelecesse as regras gerais que devem ser seguidas pelos agentes que compõem o Sistema Nacional de Crédito Rural (SNCR), por exemplo, instituições bancárias e cooperativas de crédito, para os contratos deste tipo de crédito. 
adverte que, se o prazo final para o cadastramento do imóvel rural no Cadastro Ambiental Rural (CAR) for prorrogado, a data para que este benefício exclusivo aos já cadastrados surta efeitos também o será.

Destarte, com as prorrogações das prorrogações para o cadastramento, o benefício de acesso ao crédito agrícola, que seria exclusivamente àqueles que estão devidamente cadastrados no Cadastro Ambiental Rural (CAR), não está sendo respeitado. Assim, além de não estar sendo valorizado, o proprietário/ possuidor rural que empreendeu esforços para se regularizar dentro do prazo; o benefício previsto no art. 78-A, do Código Florestal, se encontra suspenso; e os que ainda não se regularizaram ainda podem ter acesso ao crédito agrícola ${ }^{44}$.

Essa rotina governamental de prorrogação da prorrogação do prazo de inscrição no Cadastro Ambiental Rural (CAR) pode tornar inócua a lei e desmotivar aqueles que ainda não aderiram ao programa a se regulamentarem. Sobre estes últimos, pelos atuais dados, embora correspondam a uma pequena parcela, não há justificativas para que eles não obedeçam à regra geral e, se for por falta de assessoramento estatal, o Poder Público deve prontamente auxiliá-los (como os pequenos proprietários, assentamentos de terra e comunidades indígenas e quilombolas) e não procrastinar a regra. Neste ponto colaciona as ponderações da Coalizão Brasil Clima, Florestas e Agricultura ${ }^{45}$ :

Importante ressaltar que entre os produtores que ainda não se cadastraram, estãotambémmuitosagricultoresfamiliaresecomunidades tradicionais. Esse público exige tratamento diferenciado, pois sua não adequação se deve à falta de condições técnicas e financeiras para realizar o cadastro. Não se trata, portanto, de conceder mais prazo, mas sim de cobrar do Estado a responsabilidade em prover o apoio

44 O que se adverte é que a imposição do artigo 78-A do Código Florestal não terá aplicabilidade enquanto houver as prorrogações para a inscrição no Cadastro Ambiental Rural (CAR). Ou seja, não é ilegal que a instituição financeira conceda crédito agrícola ao proprietário/possuidor que ainda não esteja cadastrado no Cadastro Ambiental Rural (CAR). Mas se pondera que tal ressalva é feita considerando o conteúdo do artigo 78-A, do Código Florestal, isso porque podem ter outros dispositivos da lei florestal e outros atos normativos que já estabeleçam como pré-requisito para o acesso ao crédito agrícola o cadastramento no Cadastro Ambiental Rural (CAR).

45 "A Coalizão Brasil Clima, Florestas e Agricultura é um movimento multissetorial que se formou com o objetivo de propor ações e influenciar políticas públicas que levem ao desenvolvimento de uma economia de baixo carbono, com a criação de empregos de qualidade, o estímulo à inovação, à competitividade global do Brasil e à geração e distribuição de riqueza a toda a sociedade. Mais de 160 empresas, associações empresariais, centros de pesquisa e organizações da sociedade civil já aderiram à Coalizão Brasil. " COALIZÃO BRASIL CLIMA, FLORESTAS E AGRICULTURA. Coalizão Brasil reprova qualquer nova tentativa de prorrogação no Cadastro Ambiental Rural. Brasil, 11 de maio de 2018. Disponível em: <http://www.coalizaobr com.br/home/index.php/posicionamentos/item/813-coalizao-brasil-reprova-qualquer-nova-tentativa-de-prorrogacao-nocadastro-ambiental-rural?utm_source=Mailee\&utm_medium=email\&utm_campaign=20180606-prorroga\%C3\%A7\%C3\%A3oCAR\&utm_term=\&utm_content=T3+-+Coaliz\%C3\%A3o+Brasil+repudia+quarta+prorroga $\%$ C3\%A7\%C3\%A3o+do+Cadastro+ Ambiental+Rural>. Acesso em: 28 jul. 2018. 


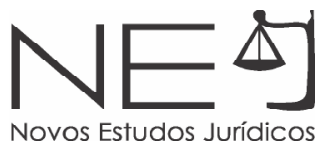

necessário para tal cadastramento. Por isso, a Coalizão Brasil solicita às autoridades que fortaleçam o apoio aos pequenos proprietários e comunidades tradicionais, tratando-os de forma diferenciada, como requer a lei, sem, com isso, colocar todo o processo de cadastramento em risco, aceitando um adiamento indiscriminado. ${ }^{46}$

Ademais, esta situação de prorrogação da prorrogação conturba a segurança jurídica, bem como consterna aqueles que já aderiram ao sistema. Logo estes entraves causados por alguns setores do governo podem desestabilizar o próprio processo estatal de fiscalização e regularização ambiental de imóveis rurais do país, o que deve ser imediatamente refutado.

\section{CONSIDERAÇÕES FINAIS}

Para que a legislação ambiental de proteção da natureza verde seja satisfatoriamente obedecida, a fiscalização deve ser robustecida, sendo imprescindível a organização global e integrada com as informações relativas aos imóveis rurais, que são os locais onde mais se concentram as áreas verdes do país.

Após as tentativas de catalogação das propriedades rurais, sobretudo das áreas verdes especialmente tuteladas, que esbarraram na falta de tecnologias, incentivos governamentais, informação e normatização para sua real implementação, o atual Código Florestal normatiza o Cadastro Ambiental Rural (CAR), aliado ao Sistema de Cadastro Ambiental Rural (SISCAR).

O Cadastro Ambiental Rural (CAR) é o registro público eletrônico, obrigatório para todos os imóveis rurais nacionais, de informações ambientais de tais propriedades, visando integrar as bases de dados de controle, monitoramento, planejamento ambiental e econômico para o combate ao desmatamento ilegal e outras interferências furtivas contra a natureza.

46 COALIZÃO BRASIL CLIMA, FLORESTAS E AGRICULTURA. Coalizão Brasil reprova qualquer nova tentativa de prorrogação no Cadastro Ambiental Rural. Brasil, 11 de maio de 2018. Disponível em: <http://www.coalizaobr.com.br/ home/index.php/ posicionamentos/item/813-coalizao-brasil-reprova-qualquer-nova-tentativa-de-prorrogacao-no-cadastro-ambiental-rural?utm_ source=Mailee\&utm_medium=email\&utm_campaign=20180606-prorroga\%C3\%A7\%C3\%A3o-CAR content=T3+-+Coaliz\%C3\%A3o+Brasil+repudia+quarta+prorroga $\% \mathrm{C} 3 \% \mathrm{~A} 7 \% \mathrm{C} 3 \% \mathrm{~A} 30+$ do+Cadastro+ \&utm_term=\&utm Acesso em: 28 jul. 2018. 
A implantação nacional do Cadastro Ambiental Rural (CAR) está evoluindo satisfatoriamente, alcançado números expressivos e colaborando com a fiscalização do meio ambiente equilibrado pelo Estado e pelos próprios cidadãos. Isso porque a plataforma on-line do Sistema de Cadastro Ambiental Rural (SICAR) é pública e de fácil manuseio, seja para aqueles que queiram se cadastrar ou apenas consultar os dados, e são apresentadas informações atualizadas.

Ademais, a plataforma digital do Cadastro Ambiental Rural (CAR) condiz com a realidade brasileira e com as novas tecnologias, tornando mais transparente, célere, econômico e acessível o processo de cadastramento dos imóveis rurais e de localização das áreas ambientais juridicamente tuteladas.

No entanto, o maior impasse para a abrangência total do instrumento deriva de ações do próprio Poder Público, que posterga a data limite de inscrição dos imóveis rurais no Cadastro Ambiental Rural (CAR) tanto pela via legislativa quanto executiva.

Logo, as prorrogações das prorrogações precisam ser prontamente refutadas pelas instituições estatais e pelos cidadãos, a fim de que o Cadastro Ambiental Rural (CAR) e seu respectivo sistema alcancem a totalidade dos imóveis rurais brasileiros e, inclusive, a lei florestal e a sua devida respeitabilidade.

Frisa-se que, utilizando o Cadastro Ambiental Rural (CAR) e o Sistema de Cadastro Ambiental Rural (SICAR), serão otimizadas a catalogação e a organização dos dados sobre os imóveis rurais e o patrimônio florestal em seus perímetros, corroborando para a fiscalização da proteção e da manutenção da natureza verde e identificação dos responsáveis por medidas prejudiciais e desmatamentos destas áreas. Além do mais, tornam-se mais transparentes e acessíveis à coletividade as informações sobre a proteção das florestas.

Nota-se também que a importância da não continuidade das prorrogações para que os imóveis rurais sejam cadastrados no Cadastro Ambiental Rural (CAR) implica diretamente na segurança jurídica, na efetividade da lei florestal e na eficiência do Poder Público. E inclusive em beneficiar aqueles que atenderam aos prazos de regularização ambiental do imóvel nos moldes do artigo 78-A, do Código Florestal, relacionado ao acesso de crédito agrícola. 
Destarte, com o Cadastro Ambiental Rural (CAR) e o Sistema de Cadastro Ambiental Rural (SICAR) devidamente implantados - o que se alcançará se as prorrogações para o cadastramento não se perpetuarem -, a fiscalização e o monitoramento das áreas verdes especialmente tuteladas estarão otimizadas por este instrumento, possibilitando a efetiva proteção ambiental.

\section{REFERÊNCIAS DAS FONTES CITADAS}

BARBOSA, Kelly de Souza; LEHFELD, Lucas de Souza. O Cadastro Ambiental Rural (CAR) e a sua efetivação integral: Até quando será postergada?. In: LEHFELD, Neide Aparecida de Souza (Cood. Geral). Anais de Pesquisa 2017: $18^{\circ}$ Congresso de Iniciação Científica e Pesquisa (CONIC). Ribeirão Preto: Universidade de Ribeirão Preto (UNAERP), 2017. p. 435-436. Disponível em: <http://www.unaerp.br/images/2017RPnews/Anais_18_Conic-20171031-WEB.pdf>. Acesso em: 17 jul. 2018.

CARVALHO, Délton Winter de. Gestão Jurídica Ambiental. São Paulo: Revista dos Tribunais, 2017.

COALIZÃO BRASIL CLIMA, FLORESTAS E AGRICULTURA. Coalizão Brasil reprova qualquer nova tentativa de prorrogação no Cadastro Ambiental Rural. Brasil, 11 de maio de 2018. Disponível em: <http://www.coalizaobr.com.br/home/index.php/posicionamentos/ item/813-coalizao-brasil-reprova-qualquer-nova-tentativa-de-prorrogacao-no-cadastroambiental-rural?utm_source $=$ Mailee\&utm_medium $=$ email\&utm_campaign $=20180606$ prorroga\%C3\%A7\%C3\%A3o-CAR\&utm_term=\&utm_content=T3+-+Coaliz\%C3\%A3o+Bras il +repudia +quarta + prorroga $\% \mathrm{C} 3 \% \mathrm{~A} 7 \% \mathrm{C} 3 \% \mathrm{~A} 3 \mathrm{o}+\mathrm{do}+$ Cadastro+Ambiental+Rural>. Acesso em: 28 jul. 2018.

EMBRAPA - EMPRESA BRASILEIRA DE PESQUISA AGROPECUÁRIA. Módulos fiscais. Brasília: [2018?]. Disponível em: <https://www.embrapa.br/codigo-florestal/area-de-reserva-legalarl/modulo-fiscal>. Acesso em: 11 ago. 2017.

LASKOS, André Arruda; CAZELLA, Ademir Antônio; REBOLLAR, Paola Beatriz May. O Sistema Nacional de Cadastro Rural: história, limitações atuais e perspectivas para a conservação ambiental e segurança fundiária. Desenvolvimento e Meio Ambiente, Curitiba, v. 36, p.189199, 30 abr. 2016. Disponível em: <http://revistas.ufpr.br/made/article/view/39124>. Acesso em: $01^{\circ}$ jul. 2018.

LAUDARES, Sarita de Alcântara; SILVA, Kmila Gomes da; BORGES, Luís Antônio Coimbra. Cadastro Ambiental Rural: uma análise da nova ferramenta para regularização ambiental do Brasil. Desenvolvimento e Meio Ambiente, Curitiba, v. 31, p.111-122, ago. 2014. Disponível em: <http://revistas.ufpr.br/made/article/view/33743>. Acesso em: 28 jul. 2018.

LEHFELD, Lucas de Souza; CARVALHO, Nathan Castelo Branco de; BALBIM, Leonardo Nassif. Código Florestal comentado e anotado: artigo por artigo. 3. ed. São Paulo: Método, 2015. 
MMA - Ministério do Meio Ambiente. CONAMA: SISNAMA - Sistema Nacional do Meio Ambiente. Brasília, [2018?]. Disponível em: <http://www.mma.gov.br/port/conama/estr1. cfm>. Acesso em: 03 ago. 2018.

MMA - Ministério do Meio Ambiente. SINIMA: Sistema Nacional de Informações sobre o meio ambiente. Brasília, 2001. Disponível em: <http://www.mma.gov.br/port/se/sinima/capa/ corpo.html>. Acesso em: 03 ago. 2018.

OBSERVATÓRIO DO CÓDIGO FLORESTAL. O prazo para cadastramento no CAR não deve ser prorrogado uma terceira vez indistintamente. Brasília, 07 jul. 2017. Disponível em: <http:// www.observatorioflorestal.org.br/noticia/o-prazo-para-cadastramento-no-car-nao-deveser-prorrogado-uma-terceira-vez-indistintamente>. Acesso em: 11 jul. 2018.

SFB - SERVIÇO FLORESTAL BRASILEIRO. Módulos de Relatórios. In: Cadastro Ambiental Rural. Brasília, 30 jun. 2018. Disponível em: <http://www.florestal.gov.br/modulo-de-relatorios>. Acesso em: 04 ago. 2018.

SFB - SERVIÇO FLORESTAL BRASILEIRO. Cadastro Ambiental Rural (CAR): Boletim Informativo, dados até 30 de junho de 2018. Brasília, 30 jun. 2018. Disponível em: < http://www.florestal. gov.br/documentos/car/boletim-do-car/3735-boletim-informativo-julho-de-2018/file>. Acesso em: 04 ago. 2018.

SICAR - SISTEMA DE CADASTRO AMBIENTAL RURAL. Sobre: O que é o CAR?. [2018?]. Disponível em: <http://www.car.gov.br/\#/sobre>. Acesso em: 28 jul. 2018. 